\title{
Farcial futile pharmacy fiasco -let pharmacy return to its apothecary roots!
}

Mister Seun Ayoade

Independent Researcher. Alumnus, College of Medicine University of Ibadan, Oyo State, Nigeria.

*Corresponding Author: Mister Seun Ayoade, Independent Researcher. Alumnus, College of Medicine University of Ibadan, Oyo State,

Nigeria.

Received date: March 19, 2021; Accepted date: March 30, 2021; Published date: April 02,2021

Citation: Mister Seun Ayoade (2021) Farcial futile pharmacy fiasco -let pharmacy return to its apothecary roots. J. Pharmaceutics and Pharmacology Research. 4(3); DOI: 10.31579/2693-7247/035

Copyright: (C) 2021, Mister Seun Ayoade, This is an open access article distributed under the Creative Commons Attribution License, which permits unrestricted use, distribution, and reproduction in any medium, provided the original work is properly cited.

INQUIRER - Congratulations! You are now a pharmacist.

PHARMACIST- Thank you.

INQUIRER-So what can you do as a pharmacist?

PHARMACIST-I can sell people drugs after the doctor prescribes them.

INQUIRER-Can you manufacture drugs?

PHARMACIST- No I cannot. Chemists, chemical engineers, pharmaceutical scientists and pharmaceutical manufacturing technicians and technologists can do that.

INQUIRER- So all you do is read the prescription, check your shelf and hand the drugs over to the patient.

PHARMACIST-Basically, yes.

INQUIRER-And you spent 5 years in university to learn that? My 10 year old can do that. Anyone who can read the doctor's writing can do that. And these days with many doctors handing over electronic prescriptions you don't even have to be able to read the squiggly scribbles.
PHARMACIST [visibly angry]-Oh shut up! Pharmacists can also recommend ointments and creams for a cut or a bruise or burn, rash or infection.

INQUIRER-So can I! I have done so many times. And I didn't have to study for 5 years to learn that.

PHARMACIST-I can give injections!!!

INQUIRER-So can the heroin addict on the street. You don't need to study for years to be able to find a vein. A layman can read a prescription and sell a drug. A layman can recommend creams and lotions. A layman can give a hypodermic injection. But a layman cannot mix chemicals together and produce a tablet or a capsule or a syrup. That is what a pharmacist should be able to do. I'd go to college for 4 years to be able to do that.

PHARMACIST -Shame on you! This discussion is over.

Below are some of the most important drugs ever invented in the last 100 plus years and the discipline/profession/occupation of the inventors and discoverers.

\begin{tabular}{|l|l|l|}
\hline Drug & Inventor & Discipline \\
\hline Insulin & Sir Frederick Grant Banting & Orthopaedic surgery \\
\hline Levothyroxine & Charles Harington & Chemical Pathology \\
\hline Penicillin & Alexander Fleming & Medicine, Microbiology \\
\hline Prontosil & Gerhard Domagk & Medicine \\
\hline Cortisone & $\begin{array}{l}\text { Edward Calvin Kendall } \\
\text { Philip Showalter Hench }\end{array}$ & $\begin{array}{l}\text { Chemistry } \\
\text { Medicine }\end{array}$ \\
\hline Lidocaine & Nils Löfgren & Chemistry \\
\hline Lysergic acid diethylamide (LSD) & Albert Hofmann & Chemistry \\
\hline Chlordiazepoxide & Leo Sternbach & Chemistry \\
\hline Furosemide & Calvin L. Stevens & Chemistry \\
\hline Ketamine & Calvin L. Stevens & Chemistry \\
\hline Phenylhydrazine & Emil Fischer & Chemistry \\
\hline Paracetamol & & \\
\hline Phenazone & Harmon Northrop Morse & Chemistry \\
\hline Benzocaine & Ludwig Knorr & Chemistry \\
\hline
\end{tabular}




\begin{tabular}{|l|l|l|}
\hline Quinazoline & August Bischler & Chemistry \\
\hline Amphetamine & Lazăr Edeleanu & Chemistry \\
\hline Adrenaline & Takamine Jōkichi & Chemistry \\
\hline Arsphenamine & Alfred Bertheim & Chemistry \\
\hline Vitamin C & Tadeusz Reichstein & Chemistry \\
\hline Oxytocin & Henry Hallett Dale & Medicine \\
\hline Phenytoin & Heinrich Biltz & Chemistry, Natural Science \\
\hline Phenobarbital & Joseph von Mering & Medicine \\
& Franz Joseph Emil Fischer & Chemistry \\
\hline Thyroxine & Edward Calvin Kendall & Chemistry \\
\hline Ergotamine & Arthur Stoll & Chemistry \\
\hline Viagra & $\begin{array}{l}\text { Ian Osterloh } \\
\text { Robert Francis Furchgott } \\
\text { Peter Dunn } \\
\text { Nicholas Terrett }\end{array}$ & $\begin{array}{l}\text { Medicine and Surgery } \\
\text { Biochemistry } \\
\text { Chemistry } \\
\text { Chemistry }\end{array}$ \\
\hline
\end{tabular}

There is not one pharmacist on the list! Some may say what of Sir David Jack [1924-2011] who discovered Beclometasone? He took a combined honours degree in BOTH chemistry AND pharmacy so was not a standalone pharmacist. The same thing applies to Nagai Nagayoshi [18441929] discoverer of ephedrine, who studied medicine, pharmacy AND organic chemistry. Even John Stith Pemberton (1831 to 1888) creator of Coca Cola who many pharmacists claim as "the most famous pharmacist" was actually a medical doctor! Right up to the start of the industrial revolution apothecaries were at the forefront of the discovery and invention of drugs. In those days medicine, surgery and pharmacy [apothecary] were three distinct professions. A sick person would visit the doctor (or the doctor would visit the sick person) for a diagnosis. The doctor could recommend a surgery (which the surgeon would be called upon to perform) or prescribe a medication. The patient would head for the apothecary [pharmacy] where the apothecary who also manufactured the medication would sell it to the patient. Medicine and surgery have since been combined into one profession. Pharmacy remains alone and is the worse for it! The same professional (medical doctor) today diagnoses, prescribes and cuts. The pharmacist still sells the medicine but does not manufacture it any longer. How sad!
Perhaps it is because the pharmacy profession lost its highest meaning (drug manufacture) in its disjointed transition from apothecary that the profession now desperately seeks to ape medical doctors and has become so inward looking and hostile to other professions that it will not permit even a medical doctor or a holder of a first class degree from a related discipline (e.g. pharmacology) to pursue a master's degree in pharmacy! Let pharmacy return to the apothecary model or be downgraded to a diploma occupation! [1-2] India has set an excellent example in this regard [3].

\section{References}

1. Mister Seun Ayoade. (2020) The Ongoing Erosion of Division of Labour Spells Doom for Healthcare Delivery! LOJ Phar \& Cli Res 2(2).

2. Mister Seun Ayoade. (2020) Wanted: A 21st Century Flexner. LOJ Phar \& Cli Res. 2(3).

3. Basak and Dondeti Sathyanarayana, (2010) Pharmacy Education in India, Am J Pharm Educ. 74(4): 68. C. 